\title{
A MATERIALIZAÇÃO DIGITAL E SUA SISTEMATIZAÇÃO NO PROCESSO DE DESENVOLVIMENTO DE PRODUTOS
}

\author{
Ivan Luiz de Medeiros (UFSC) \\ Gilson Braviano (Orientador - Pósdesign -UFSC)
}

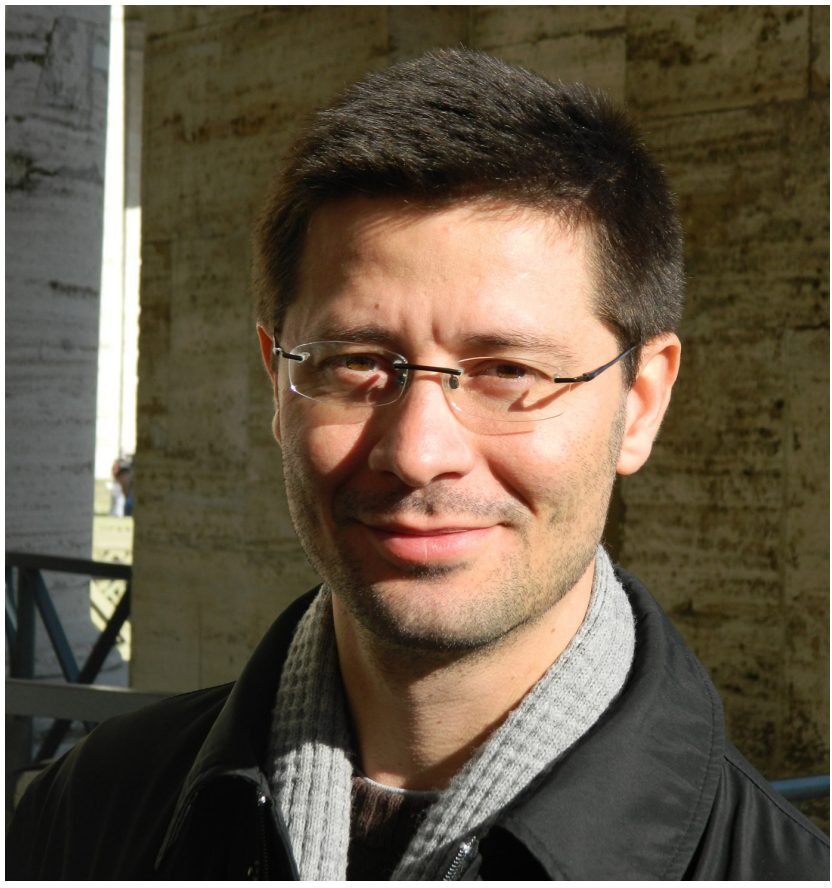

Ivan Luiz de Medeiros

É comum, no processo de Design de produtos, que o início da atividade projetual ocorra de forma abstrata, passando posteriormente para o físico. Uma alternativa que contribui para minimizar os erros nas tomadas de decisões é realizar a materialização de propostas já na fase de concepção do processo de Design. Neste aspecto se encontra o diferencial desta pesquisa, ao se focar em processos de materialização mediados por meios digitais usados já nas etapas iniciais do processo projetual para a construção de mock-ups, modelos e protótipos.

Define-se o protótipo como sendo aquele que reproduz todas as características do produto, estéticas e funcionais, possibilitando testes de usabilidade. Modelos podem ser classificados em: Volumétrico (sem muitos detalhes); Estrutural (verificar integração de componentes e peças); Funcional (testar funcionamento de sistemas); Ergonômico (escala real) e Modelo de Apresentação (comunicar com clientes). Já o mock-up é uma materialização preliminar em tamanho real, construído com materiais de baixo custo.
Objetivou-se desenvolver um Protocolo de identificação e priorização de critérios para a realização de Materialização Digital (referente a aplicação dos equipamentos de corte a laser, impressão 3D e usinagem com CNC para a produção de mock-ups, modelos e protótipos) ainda na fase de conceituação.

A partir destas potencialidades apresentadas, pelas tecnologias da Materialização Digital em conjunto com a quantidade de informação que os modelos físicos desencadeiam no processo decisório, acredita-se que essas informações apresentam importância para os designers responsáveis pelo desenvolvimento de produtos, para que sejam capazes de selecionar dentre as técnicas de materialização por meios digitais, a mais adequada a ser utilizada na fase de concepção do desenvolvimento de produto, não impedindo que estas técnicas sejam aplicadas em outras etapas do processo de projeto.

$\mathrm{Na}$ metodologia utilizada nesta pesquisa houve uma revisão bibliográfica, pesquisa das ações de Materialização Digital realizadas no Laboratório PRONTO3D (UFSC), posteriormente a realização de entrevistas com quatorze pesquisadores brasileiros. $\mathrm{O}$ desenvolvimento do Protocolo em uma plataforma digital (website) e uma atividade de grupo focal composto por nove designers de produto, avaliando o protocolo desenvolvido. Foram hierarquizados critérios e criaram-se regras para compor o Protocolo, que a partir das combinações destes elementos, gera sugestões relativas à aplicação dos processos de Materialização Digital.

Os testes, realizados por meio de um site (leopardpro. com.br) elaborado especificamente para este fim, mostraram que os critérios de tomada de decisão identificados ao longo da pesquisa abrangem os aspectos relevantes quanto a aplicação de cortadora laser, impressão 3D e usinagem com CNC. As sugestões de aplicação da Materialização Digital oferecidas pelo sistema contribuem assertivamente para as dúvidas dos designers de produto quanto à seleção dos processos técnicos. 


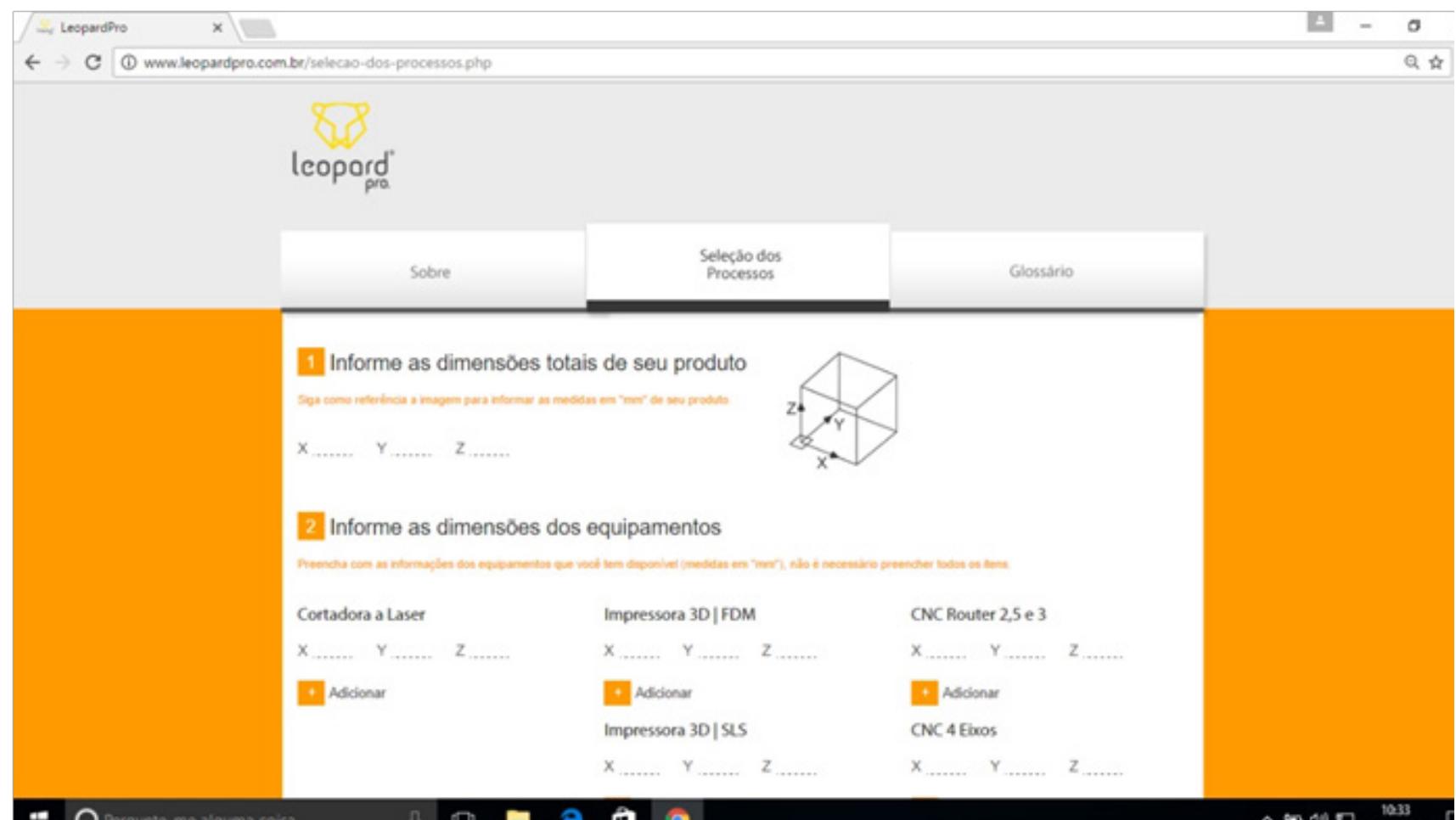

Fonte: Autor

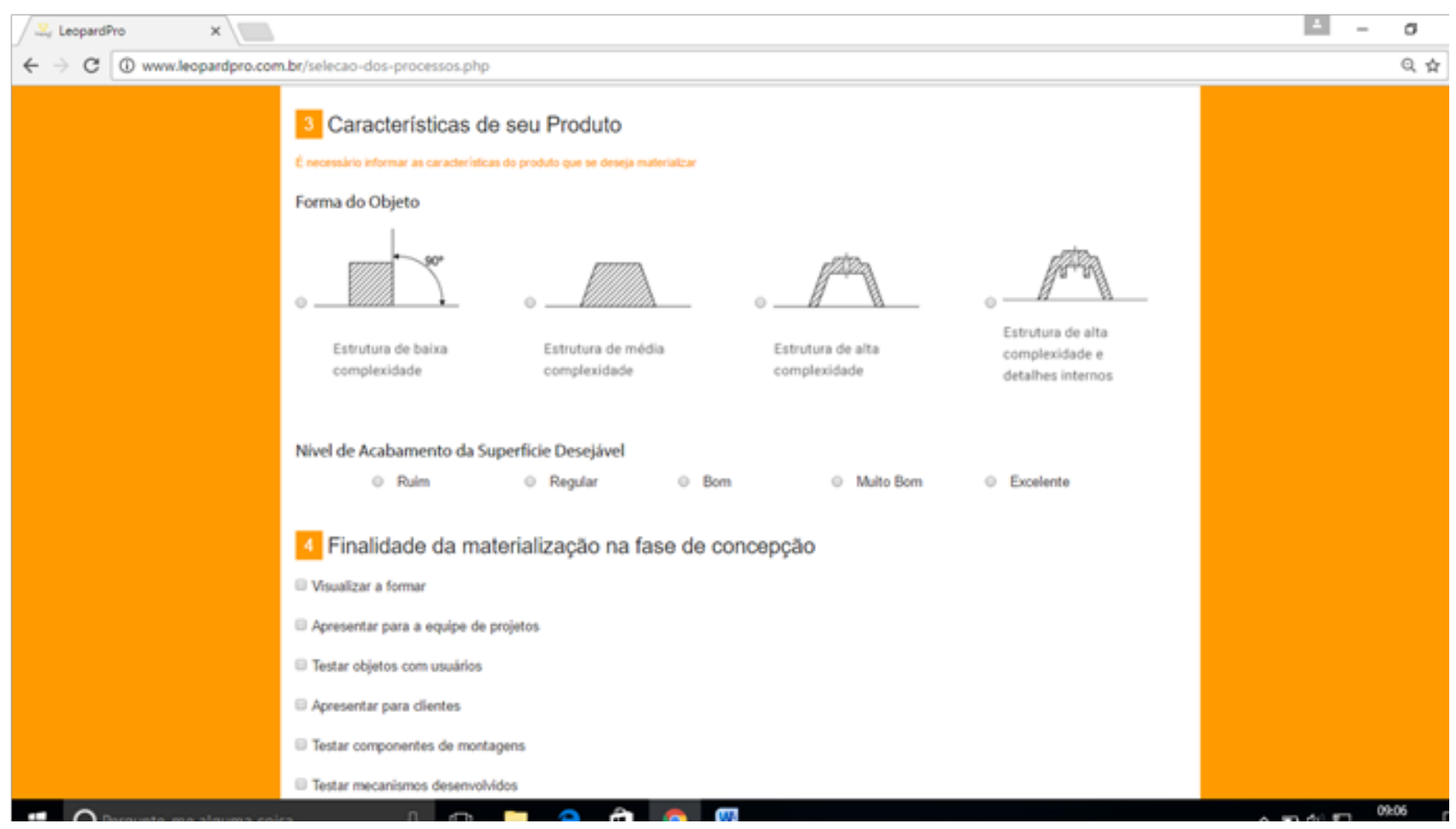

Fonte: Autor 